Research Paper

\title{
Molecular basis of high-level ciprofloxacin resistance in Neisseria gonorrhoeae strains from Shandong Province, China
}

\author{
L.H. Zhao, S.P. Zhao \\ Department of Laboratory, Taian Central Hospital, Taian, P.R. China.
}

Submitted: October 29, 2011; Approved: July 2, 2012.

\begin{abstract}
In the study, the ciprofloxacin resistance rate was $100 \%$. High-level ciprofloxacin resistance rate was $63.55 \%$. Sixteen different mutation patterns involved in the formation of ciprofloxacin resistance were identified. The most prevalent were patterns P7 (25.2\%), P8 (15.0\%), P9 (11.2\%), P1 (10.3\%), and P5 (10.3\%). All of the $107 N G$ isolates analyzed for mutations in the study have demonstrated a change of Ser-91 $\rightarrow$ Phe in the gyrA gene, and all except one have demonstrated a change in position 95 of the amino acid sequence. All of the 68 high-level QRNG isolates had double mutations in gyr $A$ gene combined with a single or two mutations in $\operatorname{par} C$ gene. It is most important that a new mutation site of Ile-97 $\rightarrow$ Met in gyrA and a new mutation of Leu-106 $\rightarrow$ Ile in $\operatorname{parC}$ were found in the study, both leading to high-level ciprofloxacin resistance (MIC values, $8 \mu \mathrm{g} / \mathrm{mL}, 32 \mu \mathrm{g} / \mathrm{mL}$, respectively). Therefore, we confim that gyrA mutations are necessary for the fluoroquinolone resistance phenotype and $\operatorname{parC}$ mutations are correlated intimately with high-level fluoroquinolone resistance. In China fluoroquinolone resistance in Neisseria gonorrhoeae strains is very serious and the new mutation sites in the fluoroquinolone resistance-determining regions emerge more and more quickly. Hence, in China fluoroquinolones, which are used to treat gonorrhoea presently, should be substituted by a new antibiotics.
\end{abstract}

Key words: Neisseria gonorrhoeae, ciprofloxacin resistance, high-level, molecular analysis.

\section{Introduction}

Neisseria gonorrhoeae ( $N$. gonorrhoeae) is the pathogen of gonorrhoea, one of the most common sexually transmitted diseases worldwide. In China, gonorrhea is the second one of the sexually transmitted diseases, with a cumulative total of 119,824 reported cases in 2009 (http://www.chinacdc.cn/en/, 2010). Neisseria gonorrhoeae urogenital infection leads to pelvic inflammatory disease and infertility. Therefore, it is very important for early detection and appropriate treatment of $N$. gonorrhoeae infection. In the face of widespread penicillin resistance, fluoroquinolones have been used as an effective antimicrobial agent for treatment of $N$. gonorrhoeae infection. However, presently fluoroquinolone-resistance in $N$. gonorrhoeae (QRNG) has emerged and increased rapidly in the United States, Western Europe, and Asia (Fiorito et al., 2001; Bala et al., 2003; Vereshchagin et al., 2004; Yong et al., 2004; http://www.who.int/en/, 2004; Xie et al.,
2006; Allen et al., 2011; Angeliki et al., 2011;). In China, the range of the rate of fluoroquinolone resistance is about $30 \%$ to $80 \%$, depending on the regions studied ( $\mathrm{Su}$ et al., 2004; Liu et al., 2006; Tu et al., 2006).

Fluoroquinolone resistance in $N$. gonorrhoeae has been shown to be due to point mutations at Ser-91 and Asp-95 in the gyrA gene (Fiorito et al., 2001). Besides this, parC mutation has also been involved in high-level fluoroquinolone resistance of $N$. gonorrhoeae (Lindback et al., 2002), but parC mutations in isolation do not appear to be associated with antimicrobial resistance (Zhou et al., 2004). Zafar Sultan shows that double alterations at Ser-91 and Asp-95 in gyrA plus a single or double parC alteration(s) play an important role in the development of highlevel fluoroquinolone resistance in $N$. gonorrhoeae (Sultan et al., 2004). Isolates with only gyrA mutations has lower MICs than those with mutations in both $g y r A$ and $\operatorname{parC}$ gene (Wang et al., 2006; Yang et al., 2006). 
In this study we investigated the occurrence of ciprofloxacin resistance among 107 isolates of $N$. gonorrhoeae collected from Shandong Province from 2007 to 2011, and analyzed the molecular basis of ciprofloxacin resistance in the Neisseria gonorrhoeae isolates from Shandong Province, China.

\section{Materials and Methods}

\section{Bacterial strains}

107 non-duplicate isolates of $N$. gonorrhoeae were collected from patients who attended sexually transmitted disease (STD) clinics in Tai'an between June 2007 and June 2011. The age range of the patients was from 18 to 51 years (mean, 29.6 years), and the ratio of male to female patients was 1.2:1. The swab specimens were isolated initially on Thayer-Martin agar plates, then subcultured onto chocolate agar plates in a $5 \% \mathrm{CO}_{2}$ incubator at $35^{\circ} \mathrm{C}$ for 24 to $48 \mathrm{~h}$, and then identified by colony morphology, Gram stain and oxidase reaction, followed by carbohydrateutilization studies of glucose, maltose, fructose and sucrose (API NH, bioMérieux). Colonies collected from plates and supplemented with $8 \%$ skimmed milk and $10 \%$ fetal calf serum were stored at $-70{ }^{\circ} \mathrm{C}$.

\section{Antimicrobial susceptibility testing}

MICs of ciprofloxacin (Bayer AG, Germany) were determined by an agar dilution method with GC agar base (bioMérieux, France) supplemented with PolyViteX (bioMérieux, France) according to the Clinical and Laboratory Standards Institute (National Committee for Clinical Laboratory Standards, 2006). N. gonorrhoeae ATCC 49226 (American Type Culture Collection, USA) was used as a control. All tests were performed in triplicate. The MIC $(\mu \mathrm{g} / \mathrm{mL})$ was defined as the concentration at which no colony was detected after agar plates were incubated at $35{ }^{\circ} \mathrm{C}$ in $5 \% \mathrm{CO}_{2}$ for $24 \mathrm{~h}$. The criteria for ciprofloxacin resistance in $N$. gonorrhoeae isolates was MIC values $\geq 1 \mu \mathrm{g} / \mathrm{mL}$ (National Committee for Clinical Laboratory Standards, 2006). The criteria for highlevel ciprofloxacin resistance in $N$. gonorrhoeae isolates was MIC values $\geq 4 \mu \mathrm{g} / \mathrm{mL}$ (Allen et al., 2011).

\section{$\mathrm{QRDR}_{\mathrm{s}}$ amplification and sequencing}

The fluoroquinolone resistance-determining regions (QRDRs) were amplified with the primers designed by Primer Premier 5.0 (Premier, Canada). The forward primer for the gyrA gene was 5'-GAT GTA TCA ATC CGC CAC G-3' and the reverse was 5'-AGC AGT TGA CGA GCA
GTG TG-3', leading to a product of $529 \mathrm{bp}$ from position 7 to 535. The PCR mixtures were composed of $0.5 \mu \mathrm{L}$ of each of primers $(25 \mu \mathrm{M}$, each), $0.5 \mu \mathrm{L}$ of Ex-Taq $(5 \mathrm{U} / \mu \mathrm{L})$ (TaKaRa Biotech., Dalian, China), $2.5 \mu \mathrm{L}$ of $10 \mathrm{LA}$ PCR Buffer II $\left(\mathrm{Mg}^{2+}\right.$ Free), $2.5 \mu \mathrm{L}$ of $\mathrm{MgCl}_{2}(25 \mathrm{mM}), 4 \mu \mathrm{L}$ of dNTP mixtures ( $2.5 \mathrm{mM}$, each), $5 \mu \mathrm{L}$ of template DNA, and $9.5 \mu \mathrm{L}$ of the distilled water added to a final volume of $25 \mu \mathrm{L}$. The PCR for the gyrA gene was carried out as follows: $93{ }^{\circ} \mathrm{C}$ denaturation for $2 \mathrm{~min}$, followed by 35 cycles of denaturation at $93{ }^{\circ} \mathrm{C}$ for $45 \mathrm{~s}$, annealing at $54{ }^{\circ} \mathrm{C}$ for $55 \mathrm{~s}$ and extension at $72{ }^{\circ} \mathrm{C}$ for $60 \mathrm{~s}$, with final extension at $72{ }^{\circ} \mathrm{C}$ for $3 \mathrm{~min}$. The forward primer for amplification of the $\mathrm{parC}$ gene was 5'-CGC TTC CCA TAC TGA TTC CAA C-3' and the reverse was 5'-TTG TGC TAC GCA ATC TCG GT-3', leading to a product of $552 \mathrm{bp}$ from position 18 to 569. The PCR mixtures were composed of $0.5 \mu \mathrm{L}$ of each of primers $(25 \mu \mathrm{M}$, each), $1.0 \mu \mathrm{L}$ of $E x-\operatorname{Taq}(5 \mathrm{U} / \mu \mathrm{L})$ (TaKaRa Biotech., Dalian, China), $2.5 \mu \mathrm{L}$ of 10LA PCR Buffer II $\left(\mathrm{Mg}^{2+}\right.$ Free), $2.5 \mu \mathrm{L}$ of $\mathrm{MgCl}_{2}(25 \mathrm{mM}), 4 \mu \mathrm{L}$ of dNTP mixtures (2.5 mM, each), $5 \mu \mathrm{L}$ of template DNA, and $9.0 \mu \mathrm{L}$ of the distilled water added to a final volume of $25 \mu \mathrm{L}$. The PCR for the $\operatorname{parC}$ gene was carried out as follows: $95^{\circ} \mathrm{C}$ denaturation for $2 \mathrm{~min}$, followed by 35 cycles of denaturation at $95{ }^{\circ} \mathrm{C}$ for $30 \mathrm{~s}$, annealing at $52{ }^{\circ} \mathrm{C}$ for $60 \mathrm{~s}$ and extension at $72{ }^{\circ} \mathrm{C}$ for $60 \mathrm{~s}$, with final extension at $72{ }^{\circ} \mathrm{C}$ for $2 \mathrm{~min}$. The amplified fragments was purified by Genomic DNA Purification Kit (Promega Wizard, USA), and the PCR products were sent to Invitrogen Biotech.(Shanghai, China) for sequence analysis on an $\mathrm{ABI} 373$ automatic sequencer (Applied Biosystems, USA), and data were aligned with QRDR sequences for amino acids (aa) 91 to 95 of gyr (GenBank accession number $\underline{\mathrm{U} 08810}$ ) and aa 86 to 91 of parC (GenBank accession number U08907).

\section{Results}

\section{Susceptibilities to ciprofloxacin}

The ciprofloxacin susceptibilities of 107 Chinese gonococcal isolates were shown in Table 1. All of the 107 isolates were resistant to ciprofloxacin (MICs, $\geq 1 \mu \mathrm{g} / \mathrm{mL}$ ). Of the 107 isolates tested, 68 isolates demonstrated high-level resistance to ciprofloxacin (MICs, $\geq 4 \mu \mathrm{g} / \mathrm{mL}$ ).

\section{Mutation patterns in the gyrA and parC genes}

Table 2 showed the mutation patterns found in gyrA and parC genes in 107 ciprofloxacin-resistant isolates. Six-

Table 1 - Ciprofloxacin MICs for 107 Chinese N. gonorrhoeae isolates.

\begin{tabular}{|c|c|c|c|c|c|c|c|c|c|c|c|c|c|c|c|c|}
\hline \multirow[t]{2}{*}{ Agent } & \multicolumn{13}{|c|}{ No. of strains with MIC $(\mu \mathrm{g} / \mathrm{mL})$ of: } & \multirow{2}{*}{$\begin{array}{l}\text { No. of highly re- } \\
\text { sistant strains (\%) }\end{array}$} & \multirow[t]{2}{*}{ MIC50 } & \multirow[t]{2}{*}{ MIC90 } \\
\hline & 0.015 & 0.03 & 0.06 & 0.125 & 0.5 & 1 & 2 & 4 & 8 & 16 & 32 & 64 & 128 & & & \\
\hline Ciprofloxacin & & & & & & 17 & 22 & 30 & 22 & 8 & 6 & 1 & 1 & $68(63.55 \%)$ & 4 & 16 \\
\hline
\end{tabular}




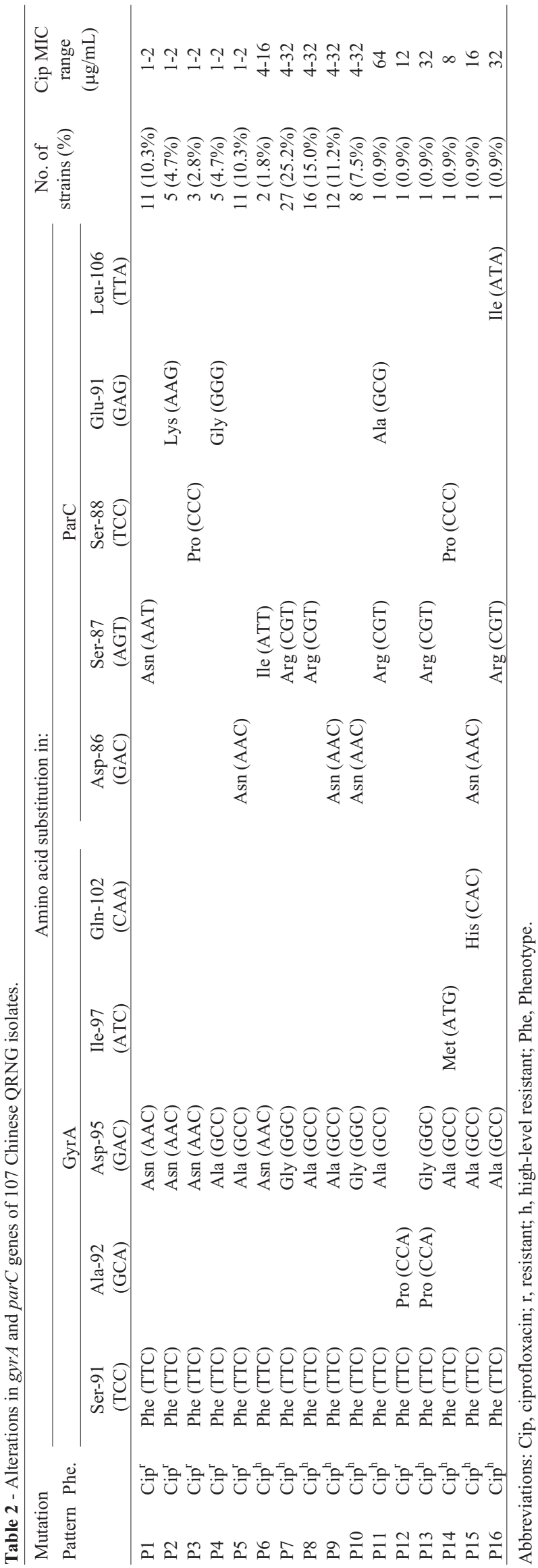

teen different mutation patterns were characterized. Seven mutation sites were found on the gyrA gene, leading to seven amino acid changes. Twelve mutation sites were found on the $\operatorname{parC}$ gene, leading to nine amino acid changes. Three silent mutations in codons 104 (TAT to TAC), 129 (GCG to GCA), and 131 (CTC to CTG) of parC genes were detected. These silent mutations occurred in 60 QRNG strains (56.1\%).

\section{Discussion}

Nowadays, in China, fluoroquinolones have been continually used to treat infections caused by $N$. gonorrhoeae despite widespread resistance. The continued use of fluoroquinolone antibiotics results in a substantial of fluoroquinolones resistant $N$. gonorrhoeae strains and raises the possibility that horizontal gene transfer is an important mechanism for the acquisition of resistance (Loubna et al., 2010).

In this study the ciprofloxacin resistance rate was $100 \%$. High-level resistance to ciprofloxacin (MICs, $\geq$ $4 \mu \mathrm{g} / \mathrm{mL}$ ) was $63.55 \%$ (Table 1 ). Therefore, this antibiotic should not be recommended for treatment of gonococcal infections in the Shandong Province, China. In this study sixteen different mutation patterns involved in the formation of ciprofloxacin resistance were identified. The most prevalent were patterns P7 $(25.2 \%)$, P8 (15.0\%), P9 (11.2\%), P1 (10.3\%), and P5 (10.3\%), which differed from those reported in other countries and regions (Vereshchagin et al., 2004; Yong et al., 2004; Angeliki et al., 2011;). All of the $107 N G$ isolates analyzed for mutations in the study have demonstrated a change of Ser-91 $\rightarrow$ Phe in the gyrA gene, and all except one have demonstrated a change in position 95 of the amino acid sequence. All of the 68 high-level QRNG isolates in the study had double mutations in position 91 and 95 in gyrA gene combined with a single or two mutations in $\operatorname{parC}$ gene (Table 2). It is most important that a new mutation site of Ile-97 $\rightarrow$ Met in gyrA and a new mutation of Leu-106 $\rightarrow$ Ile in parC were found in this study, both leading to high-level ciprofloxacin resistance (MIC values, $8 \mu \mathrm{g} / \mathrm{mL}, 32 \mu \mathrm{g} / \mathrm{mL}$, respectively) (Table 2). It shows that in China fluoroquinolone resistance in Neisseria gonorrhoeae strains is very serious and that the new mutation sites in the fluoroquinolone resistance-determining regions emerge more and more quickly. Therefore, in China fluoroquinolones, which are used to treat gonorrhoea presently, should be substituted by a new antibiotics.

\section{Acknowledgments}

Tai'an central hospital (Tai'an, China) financed this research. 


\section{References}

Allen VG, Farrell DJ, Rebbapragada A, Tan J, Tijet N, Perusini SJ, Towns L, Lo S, Low DE, Melano RG (2011) Molecular Analysis of Antimicrobial Resistance Mechanisms in Neisseria gonorrhoeae Isolates from Ontario, Canada. Antimicrob Agents Chemother 55:703-712.

Angeliki M, Eva T, Eirini S, Daniel G, Vivi M, Brian GS (2011) Analysis of emergence of quinolone-resistant gonococci in Greece by combined use of Neisseria gonorrhoeae multiantigen sequence typing and multilocus sequence typing. J Clin Microbiol 49:1196-1201.

Bala M, Ray K, Kumari S (2003) Alarming increase in ciprofloxacin- and penicillin-resistant Neisseria gonorrhoeae isolates in New Delhi, India. Sex Transm Dis 30:523-525.

Centers for Disease Control and Prevention (2005) Neisseria Gonorrhoeae Reference Strains for Antimicrobial Susceptibility Testing. Centers for Disease Control and Prevention, Atlanta, 10 pp.

Chinese Centre for Disease Control and Prevention (2010) The announcement of nation legal infectious disease epidemic situation in January, 2010 and 2009 year by the Mistry of Health, the People's Republic of China. http://www.chinacdc.cn/en/.

Fiorito S, Galarza P, Pagano I, Oviedo C, Lanza A, Smayevsky J, Weltman G, Buscemi L, Sanjuan E (2001) Emergence of high level ciprofloxacin resistant Neisseria gonorrhoeae strain in Buenos Aires, Argentina. Sex Transm Infect 77:77.

Lindback E, Rahman M, Jalal S, Wretlind B (2002) Mutations in gyr $A, \operatorname{gyr} B, \operatorname{par} C$, and $\operatorname{par} E$ in quinolone-resistant strains of Neisseria gonorrhoeae. APMIS 110:651-657.

Liu WB, Wang GJ, Jing L (2006) The antimicrobial susceptibility of Neisseria gonorrhoeae in Weihai. China J Lepr Skin Dis 22:204-206.

Loubna T, Marcos PL, Gu W, Yang Y, Xue L, Keith AC, Raphael PV (2010) Population dynamics of Neisseria gonorrhoeae in Shanghai, China: A comparative study. BMC Infect Dis 10:13.

National Committee for Clinical Laboratory Standards (2006) Methods for Dilution Antimicrobial Susceptibility Tests for Bacteria that Grow Aerobically. 7th ed. Approved standard NCCLS M7-A7. National Committee for Clinical Laboratory Standards, Wayne.
Su XH, Dai XQ, Sun HH (2004) Surveillance of antimicrobial susceptibilities of Neisseria gonorrhoeae in Nanjing City, 1999-2002. Chin J Dermatol 37:262-264.

Sultan Z, Nahar S, Wretlind B, Lindback E, Rahman M (2004) Comparison of mismatch amplification mutation assay with DNA sequencing for characterization of fluoroquinolone resistance in Neisseria gonorrhoeae. J Clin Microbiol 42:591-594.

Tu YT, Zhang LX, Lin NX (2006) Surveillance on susceptibility of Neisseria gonorrhoeae to six antimicrobial agents in Wuhan. China J Lepr Skin Dis 22:451-452.

Vereshchagin VA, Ilina EN, Malakhova MV, Zubkov MM, Sidorenko SV, Kubanova AA, Govorun VM (2004) Fluoroquinolone-resistant Neisseria gonorrhoeae isolates from Russia: Molecular mechanisms implicated. J Antimicrob Chemother 53:653-656.

Wang B, Xu JS, Wang CX, Mi ZH, Pu YP, Hui M, Ling TK, Chan CY (2006) Antimicrobial susceptibility of Neisseria gonorrhoeae isolated in Jiangsu Province, China, with a focus on fluoroquinolone resistance. J Med Microbiol 55:1251-1255.

World Health Organization (2004) Increases in fluoroquinoloneresistant Neisseria gonorrhoeae among men who have sex with men-United States, 2003, and revised recommendations for gonorrhea treatment. Morb Mortal Wkly Rep 53:335-338.

Xie GY, Ying CM, Zhou JH (2006) Study on gene mutations of Neisseria gonorrhoeae resistant to fluoroquinolone. J Diagn Concepts Pract 5:243-246.

Yang Y, Liao M, Gu WM, Bell K, Wu L, Eng NF, Zhang CG, Chen Y, Jolly AM, Dillon JA. (2006) Antimicrobial susceptibility and molecular determinants of quinolone resistance in Neisseria gonorrhoeae isolates from Shanghai. J Antimicrob Chemother 58:868-872.

Yong D, Kim TS, Choi JR, Yum JH, Lee K, Chong Y, Oh HB, Shultz T, Tapsall JW (2004) Epidemiological characteristics and molecular basis of fluoroquinolone-resistant Neisseria gonorrhoeae strains isolated in Korea and nearby countries. J Antimicrob Chemother 54:451-455.

Zhou W, Du W, Cao H, Zhao J, Yang S, Li W, Shen Y, Zhang S, Du W, Zhang X (2004) Detection of gyrA and parC mutations associated with ciprofloxacin resistance in Neisseria gonorrhoeae by use of oligonucleotide biochip technology. J Clin Microbiol 42:5819-5824.

All the content of the journal, except where otherwise noted, is licensed under a Creative Commons License CC BY-NC. 